\title{
Using Mentimeter to enhance learning and teaching in a large class
}

\author{
Ma Mohin*, Leonine Kunzwa and Sagar Patel
}

School of Engineering and Technology, University of Hertfordshire, Hatfield, UK, AL10 9AB

*Corresponding author: Mohin_017@yahoo.com

\section{(c) () (8)}

EY $\mathrm{NC}$ This work is licensed under a Creative Commons Attribution-

ShareAlike 4.0 International (CC BY-SA 4.0).

Citation: Mohin, M., Kunzwa, L., and Patel, S. (2020) Using Mentimeter to enhance learning and teaching in a large class.

\begin{abstract}
Mentimeter is a web-based Clicker, Audience Response System (ARS) or Student Response System (SRS) which allows students to answer digital questions using a mobile device. It has the potential to transform the classroom environment into a more interactive, engaging and inclusive one. In this paper, a brief literature review has been provided which addresses the benefits of using ARS including Mentimeter in a large class. Also, the mechanics behind how the workings of the Mentimeter, its features and applications have been evaluated, in order, to offer the instructors with the insights about using Mentimeter for their own practice. Finally, a case study has been explained where Mentimeter was used for the formative assessment. In the present study, a Mentimeter formative assessment model has been developed which can be implemented as a good practice in Higher Education (HE). A survey on perception of students about using Mentimeter has been assessed; from the results, it is evident that using Mentimeter has a positive impact on students' attitude and performance, learning environment and technical aspects. These results will be further discussed by linking pedagogical theories and its benefits.
\end{abstract}

\section{Keywords:}

Mentimeter, Audience Response System, classroom interaction, formative assessment, student perception 


\section{Introduction}

Teaching a large class in higher education (HE) is, both, a great challenge and an incredible opportunity. Student engagement in a large class is crucial for achieving the learning outcomes. Mentimeter is a web-based interaction tool, much like the other Audience Response System (ARS) or Clicker that can be used in a large class to engage students in active learning. In general, students answer the question such as multiplechoice question (MCQ) displayed on Mentimeter using their smartphone with the help of the Internet. They can also use other devices such as laptops and tablets with which they can access the website. By the means of Mentimeter, the teachers can assess the understanding of the students instantly and provide their feedback accordingly.

While writing about the good practice in HE, Chickering and Gamson (1987) came up with seven principles including "encourages active learning" and "gives prompt feedback'. These two principles can be implemented via Mentimeter by involving the students in structured exercises and co-operation, and letting them know what they have learnt and where they need to improve. Many lecturers such as Micheletto (2011) have attributed the lack of student engagement to the obstacle to achieving learning outcomes. However, this lack of student engagement can be eliminated by the proper use of Mentimeter (Hill and Fielden, 2017). It is possible to create interactions between learner-content, learner-instructor and learner-learner (Moore 1989) through the use of Mentimeter. The histogram feedback for MCQs (Nicol and Macfarlane-Dick, 2006) created by Mentimeter can trigger a classroom discussion which is a challenge in a large class.

With the traditional method of teaching, to assess a student's understanding, the instructor takes the answer to the question by "show-of-hand" (Cline, 2006). However, this technique is of great limitations, particularly in a large class: only a few students tend to participate; mostly the confident ones; lack of anonymity; some students incline to copy; loss of data once the hands are down (Abrahamson, 2006) and is of relatively slow process. To avoid these issues, Clickers are introduced in the modern classes. Clickers provide a more effective teaching strategy than the traditional assessment (Duzhin,and Gustafsson, 2018). Using the Clicker technology, students can answer the questions displayed on the classroom screen anonymously by using the hand-held 
device. At present, smartphone-based ARS like Mentimeter is replacing the Clickers, following the fact that it does not allow to write texts easily in the conventional device. In addition, the use of smartphone-based ARS relieves the extra burden on the lecturer to maintain the university-owned devices (Hwang et al., 2015).

It is well documented that ARS has a positive impact both for teachers and learners (Caldwell, 2007) (Kay and LeSage, 2009). The key purpose of using this technology is to break the inefficient one-way communication embedded in the traditional lectures where teachers are the only speakers and students are the listeners. Additionally, it compensates for the difficulty that students face in maintaining concentration at those lectures by promoting participation of the students in the learning process. The other advantages of using ARS are: Improvement in student attendance (Greer and Heaney, 2004); students are more focused during the lecture (Bergtrom, 2006); keeping anonymity; student engagement (Simpson and Oliver, 2007) and inclusion (Hill and Fielden, 2017); students actively discuss their misconceptions with their peers and compare the results (Draper and Brown, 2004); enhancement in learning performance of the students; teachers can modify the instructions based on student's feedback and improve the quality of teaching through a better explanation (Elliott, 2003); formative assessment (Beatty, 2004); and regular feedback on learning (Cline, 2006).

Recently, Mentimeter has started paving the way to enhance the learning and the teaching in HE. It has already been used to increase the student engagement and inclusion (Hill, D.L. and Fielden, 2017). The features of Mentimeter are quite promising to use in HE (Little, 2016) (Rudolph, 2017). There are many lecturers that are adopting Mentimeter in their individual practice. However, there is little to no pedagogic research existing on its effect in HE. The purpose of this paper is to help bridge this gap in the research work. For this, the paper will mainly deal with the beneficial effect of using Mentimeter for a large class in HE.

Caldwell (2007) published a paper on Audience Response System (ARS) by combining the review of the existing research works in pedagogy with her own research data. According to this work, ARS enhances the active learning, participation, performance, accountability and enjoyment of the students in a large class. From her colleague Michel May's unpublished work, it is evident that the use of this system in a 
mathematics course increased the number of A's earned by $4.7 \%$. In her biology class, about $88 \%$ of the students' agreed that they either "frequently" or "always" enjoyed using the ARS in class. This study proposed that ARS can be the means of introducing and monitoring peer learning methods in a large class. It can also increase the attendance, particularly when ARS points are part of the final grade. For example, the attendance in her own biology class improved when ARS points were worth just $10 \%$ of the course grade. She also pointed out that this system simulates the interaction between the lecturer and the students, provides prompt feedback, and improves the lecturer's instruction.

Kay and LeSage (2009) provided a more comprehensive review of the ARS literature and highlighted the benefits and the challenges of using this technology. According to this review, the benefits of using ARS are improvements to classroom environment, learning and assessment. For example, ARSs have been used to improve the student interaction, engagement, and attention (Draper and Brown, 2004); increase the attendance (Bullock et al., 2002), stimulate the peer and class discussion (Pelton and Pelton, 2006); provide a feedback for both the students and the instructors to improve the instruction (Caldwell, 2007); and improve their learning performance (El-Rady, 2006). They explained the challenges from the point of view of both the teacher and the student. The biggest challenges for the teachers are: Time needed to learn and set up the ARS technology (Allen and Tanner, 2005); creating an effective ARS questions (Caldwell, 2007); adequate coverage of the course material (Beatty, 2004); and the ability to respond instantaneously to a student feedback (Abrahamson, 2006). On the other hand, Student challenges include adjusting to a new method of learning (Allen and Tanner, 2005); increased confusion when multiple perspectives are discussed (Draper and Brown 2004); and negative reactions to being monitored (e.g., Abrahamson, 2006). Moreover, there are some existing technology-based challenges as well. For instance, remote devices failed to function properly (El-Redy, 2006), or students forget to bring the device in the class (Caldwell 2007).

Lam et al. (2011) surveyed the student experience towards the use of ARS. Students who used mobile phone-based ARS were more positive about their experience than the students who used conventional Clickers. For the criterion "participation with Clickers increased my interaction with the instructor", Clickers scored 4 points, whereas mobile 
phone ARS scored 4.25. According to this study, mobile phone-based ARS can address the two problems embedded with the conventional Clickers including the extra cost of the Clickers; and timely procedures required to distribute the Clickers to the students and collect it back from them.

Koppen et al. (2013) explained the benefits of the mobile device-based ARS over handheld Clickers, such as no software is needed on the lecturer's computer; no expensive clickers or receiver needed; and students can vote from different locations (big advantage for video conferencing). However, they advised not to ignore the destruction caused by the mobile device. In their study, $50 \%$ of the students preferred mobile device as ARS whereas $31 \%$ preferred Clickers and rest preferred raise of hands from 108 students. Therefore, the mobile-based device was reported to be the most significant choice.

George Cheung (2018) investigated the university teachers' perception about adopting ARS in their practice. According to this study, teachers think that ARS offers many benefits in teaching including facilitating class management, promoting teacher-student interaction and fostering formative assessment.

Recently, Hill and Fielder (2017) studied the positive effects of Mentimeter on the student engagement and inclusion. One of the aims of their work was to investigate the perceptions of the University students on the interactive online quizzes using Mentimeter and whether it improves the student engagement. In one case, Mentimeter was used for a level 4 biology module. When asked for a feedback to observe the students' perceptions of Mentimeter quizzes, 13 out of the 17 participated and the responses of the students are shown below in Figure 1. 


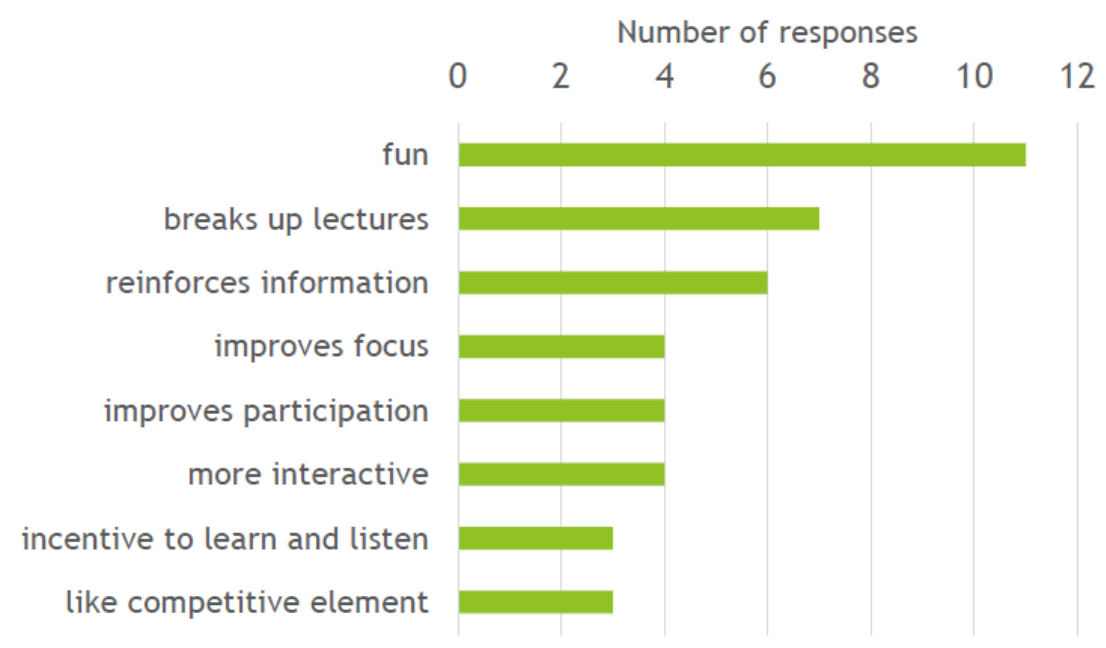

Figure 1. Students' responses to interactive Mentimeter quizzes (Hill and Fielden, 2017).

Figure 1 illustrates that more than $80 \%$ of the participants think that the interactive Mentimeter quizzes were fun. Some also support that the use of Mentimeter breaks up the lectures and reinforces the information which is necessary for quality learning. Beside these responses, all students mentioned that they would recommend using Mentimeter to the other lecturers.

From the above-mentioned studies, it is evident that ARS has a great potential of improving teaching quality in a large class. However, there is very little research available on how Mentimeter as an ARS can promote the learning experience in a large class where student engagement is difficult to achieve. Therefore, the purpose of this paper is to evaluate Mentimeter's features, investigate the effect of Mustimeter in the formative assessment for a large class and understand the corresponding students' response.

\section{Mechanism of Mentimeter, its features, and applications in the large class}

Mentimeter is a user-friendly web-based ARS system which is currently used by more than 8 million people (Mentimeter, 2017a). Lecturers, mainly, use it to ask questions to the students and take feedback from them anonymously through the Internet. The questions, answers, and feedback from a session can be stored as data, e.g. excel file 
for further analysis. The schematic of this mechanism of Mentimeter in the lecture is further shown below in Figure 2.

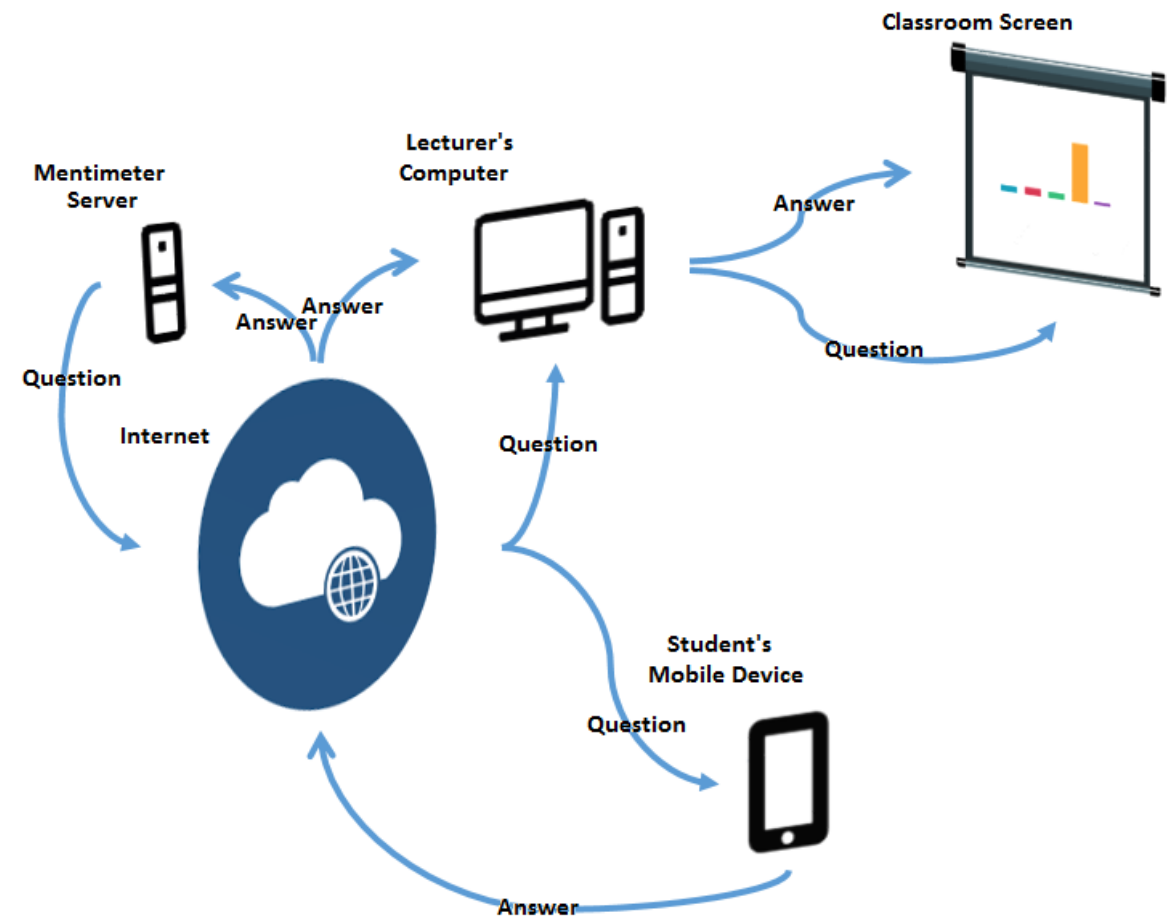

Figure 2. The schematic of the mechanism of Mentimeter in the lecture.

The key features of Mentimeter (Mentimeter, 2017b) and their applications in a large class are explained below in Table 1.

Table 1. The features of Mentimeter and their applications.

\begin{tabular}{|c|c|}
\hline Features & Applications \\
\hline Multiple Choice & $\begin{array}{l}\text { Multiple choice questions with or without question } \\
\text { image; formative assessment; enhancement of } \\
\text { student engagement, active learning, and } \\
\text { enjoyment. }\end{array}$ \\
\hline Image choice & $\begin{array}{l}\text { Aid Visual learners according to the VARK model } \\
\text { (Fleming, 2001). }\end{array}$ \\
\hline World cloud & $\begin{array}{l}\text { Emphasise the most common words submitted by } \\
\text { the students in real-time. }\end{array}$ \\
\hline
\end{tabular}




\begin{tabular}{|c|c|}
\hline Quiz & $\begin{array}{l}\text { Engage students in fun and learning-intense } \\
\text { competition. }\end{array}$ \\
\hline scales & $\begin{array}{l}\text { Evaluating the teaching activity with the learning } \\
\text { environment. }\end{array}$ \\
\hline Questions from the audience & Evaluate the lecture. \\
\hline Who will win? & $\begin{array}{l}\text { Test and develop knowledge of the students from } \\
\text { an instructor, reinforce students' learning. It } \\
\text { promotes gamification (Pettit et al., 201) in lecture, } \\
\text { energises the students and motivates them. It also } \\
\text { supports Behaviourist (Skinner, 1968) approach to } \\
\text { learning (Naismith et al., 2004). }\end{array}$ \\
\hline Quick slides & Lecture presentation. \\
\hline
\end{tabular}

An example of the Mentimeter MCQ used in the Materials and Electrical Science Module (level 4) at the University of Hertfordshire (UH) by the Authors has been presented in Figure 3. The histogram shows the response of the students to a question in percentage.

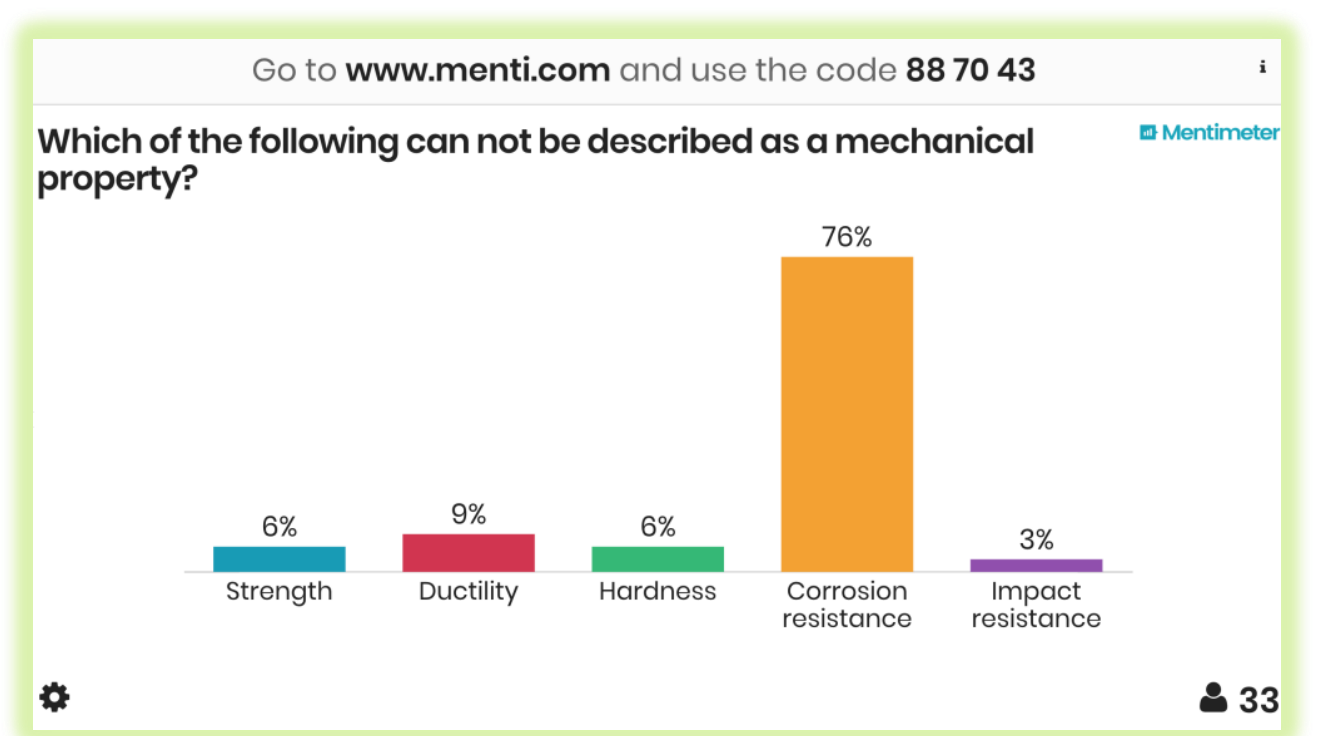

Figure 3. Mentimeter MCQ used by the Authors for Material and Electrical Science Module (level 4). 
Little (2016) provided a technological review of Mentimeter as Student Response System (SRS). This study recommended that Mentimeter can be useful for the quiz, survey and student-led teaching where the session is driven by the answers of the students to the in-class questions. By investigating his students' viewpoints, it was proposed that the Mentimeter activities can increase their engagement, focus and enjoyment.

Recently, Rudolph (2017) reported a short review of Mentimeter. According to this study, Mentimeter improves the student participation during MCQ compared to sessions without it. He identified the Mentimeter as an interactive tool to use for lecture and workshop. While giving a good review of the features of Mentimeter, he also pointed out the negative effect of world cloud feature: The fonts and words become very small if the number of answers is very large.

Lock (2017) emphasised on how the Imperial College London gains value from using Mentimeter system. In her article, she highlighted three types of learning activities which can be run using this system. These are: Formative assessment, pop quiz and exit pass. These three activities helped the lecturers access the understanding of the students about the concept, performance and understanding of the contents, respectively.

Nosek (2017) presented a comparative analysis between the Mentimeter and another web-based ARS called PollEverywhere. This analysis reported that the Mentimeter is more user-friendly, intuitive and compatible with mobile device than PollEverywhere. For example, the audience needs to input a URL into a web browser to connect to PollEverywhere whereas only a simple code can be used for Mentimeter.

\section{A case study of using Mentimter for formative assessment in the large class}

\subsection{Background}

Mentimeter was used for the formative assessment during the lecture under the level 4 Materials and Electrical Science Module in the academic year 2017-2018 at the 
University of Hertfordshire (UH). There were 262 engineering students in the class. Once the module was over, a survey was carried out among 25 students (approximately $10 \%$ ) from that class including 20 males and 5 females. The survey was used to analyse perception of the students towards using Mentimeter in a large class.

\subsection{Formative assessment}

In education, what influences students the most is not the teaching but the assessment (Gibbs and Simpson, 2004). Both the summative and formative assessment are popular to monitor learning of students in HE. Formative assessment can be taken as a good practice in pedagogy because it generates a feedback information that can be used not only by students to enhance their learning and achievement, but also by teachers to realign their teaching in response to need of the learners (Nicol and Macfariane-Dick, 2006). As a result, formative assessment improves the quality of the teaching activities, and the related learning outcomes for students. To implement a formative assessment effectively, teachers need not only substantial knowledge but also the useful classroom materials that can help them make that the inferences about what students know with respect to key domain competencies, and about what next to target for instruction (Bennett, 2011). Mentimeter can be adapted as one of these useful classroom materials for a formative assessment process as it is easy and quick to prepare, present and answer questions through Mentimeter.

In the present study, in order to implement formative assessment, Mentimeter was used to generate different types of questions including multiple choice and open-ended questions based on the lecture content. For example:

* Multiple choices (control questions), e.g., "Which of the following cannot be described as a mechanical property?"

- Word cloud (open-ended questions), e.g., "What are the applications of semiconductor?"

For a 60 mins of lecture, only 5 questions were prepared and the questions were presented at the last 15 minutes of the lecture as shown in Figure 4. Also, a common practice is to use around five questions for 50 minutes of class instructions (Elliot, 2003). Furthermore, five minutes of break was taken after the first 20 minutes of lecture so that the students can recover from the mental fatigue caused by the continuous 
lecture. Even the study by Burns (1985) has proven that the average human attention span lasts up to 20 minutes, within that period the recall in memory considerably suffers after 15-20 minutes.

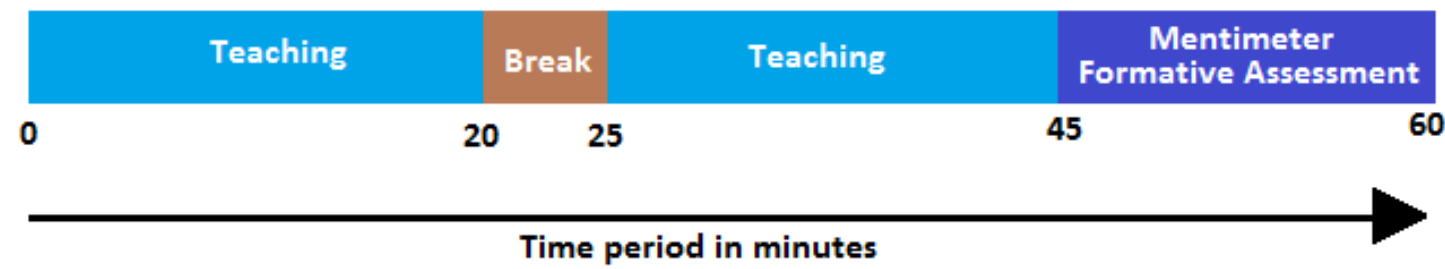

Figure 4. Teaching plan used in Materials and Electrical Science Module (level4) Lecture.

The model of the overall process to implement Mentimeter is illustrated in Figure 5. 


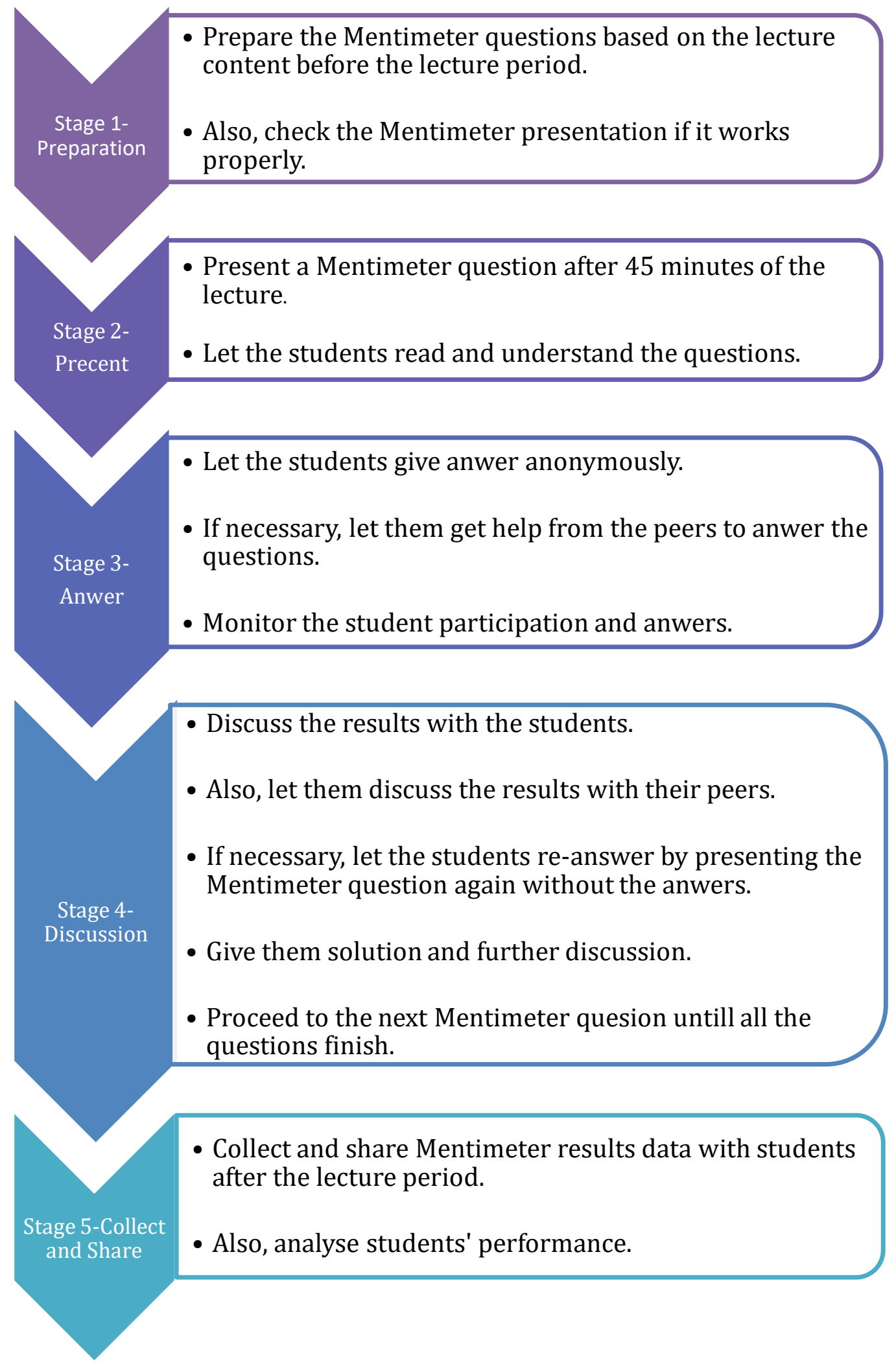

Figure 5. Mentimeter formal assessment model.

To implement Mentimeter, all the questions should be prepared before the lecture. It's better to start preparing all the questions well before the module starts so that the 
instructor can have enough time to train themselves on Mentimeter. It will also help them to produce the quality questions for formative assessment which is considered as a challenge (Caldwell, 2007). Mentimeter can be used in different stages of lecture (Hill, and Fielden, 2017) depending on the Instructor's teaching style, e.g., the Author preferred using Mentimeter towards the end of the lecture. The students should not need extra training to use the Mentimeter as it provides continuous instruction on their mobile device throughout the process. The change in the results can be shown in the form of live histogram feedback which makes the formative assessment process dynamic. The live histogram also allows to monitor the progress of the process and make it time effective. This histogram feedback can be used to trigger the classroom discussion (Nicol and Macfarlane-Dick, 2006). It is important to spend enough time in the discussion before presenting the next Mentimeter question. This helps students and their peers to share the dialogue as well as improves their understanding about the learning topic. Finally, the results should be shared with the students for their further studies after the lecture. These data is also subject to analyse and check the students' performance, and to design, and develop teaching style, and course materials.

\subsection{Students' perceptions about using Mentimeter}

A survey was carried out based on 24 questions among 25 students, which contained a scale/ranking from 1 (strongly disagree) to 5 (strongly agree) as shown in Table 2. The mean scores were consistently higher which favoured the use of Mentimeter. The bar charts of the mean scores are also provided in Figure 6 for further discussions.

Table 2. Survey results of students' perceptions about Mentimeter.

\begin{tabular}{|l|l|l|l|}
\hline $\begin{array}{l}\text { Main } \\
\text { Themes }\end{array}$ & $\begin{array}{l}\text { Murvey Questions } \\
\text { Value } \\
(\mathbf{n = 2 5})\end{array}$ & $\begin{array}{l}\text { Standard } \\
\text { Deviation }\end{array}$ \\
\hline Attitude & $\begin{array}{l}\text { 1. I prefer Mentimeter over Clicker } \\
\text { and raising hand }\end{array}$ & 4.20 & 1.02 \\
\hline $\begin{array}{l}\text { 2. I enjoyed using Mentimeter for } \\
\text { formative assessment }\end{array}$ & 4.04 & 1.00 \\
\hline
\end{tabular}




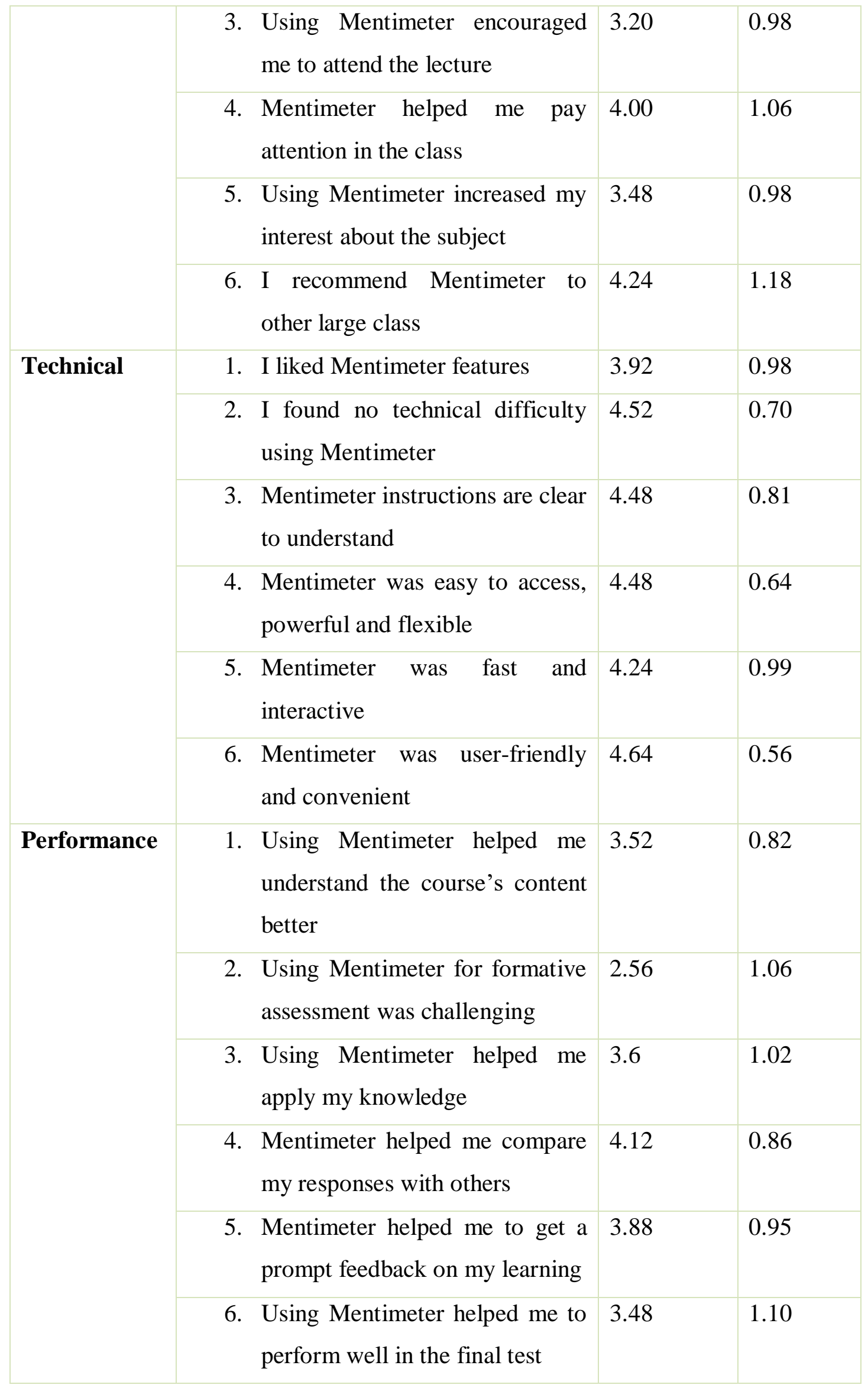




\begin{tabular}{|c|c|c|c|}
\hline $\begin{array}{l}\text { Learning } \\
\text { environment }\end{array}$ & $\begin{array}{l}\text { 1. Using Mentimeter encouraged } \\
\text { class discussion }\end{array}$ & 3.36 & 1.20 \\
\hline & $\begin{array}{l}\text { 2. Using Mentimeter improved } \\
\text { student engagement }\end{array}$ & 3.92 & 1.13 \\
\hline & $\begin{array}{l}\text { 3. Using Mentimeter improved } \\
\text { inclusion }\end{array}$ & 3.72 & 1.11 \\
\hline & $\begin{array}{l}\text { 4. Using Mentimeter improved } \\
\text { participation of the students }\end{array}$ & 4.12 & 0.86 \\
\hline & $\begin{array}{l}\text { 5. Using Mentimeter improved the } \\
\text { classroom interaction }\end{array}$ & 3.88 & 0.99 \\
\hline & $\begin{array}{l}\text { 6. Using Mentimeter encouraged } \\
\text { active learning }\end{array}$ & 3.96 & 1.04 \\
\hline
\end{tabular}

Strongly Disagree=1, Disagree=2, Neither agree nor disagree $=3$, Agree $=4$ and Strongly Agree=5.
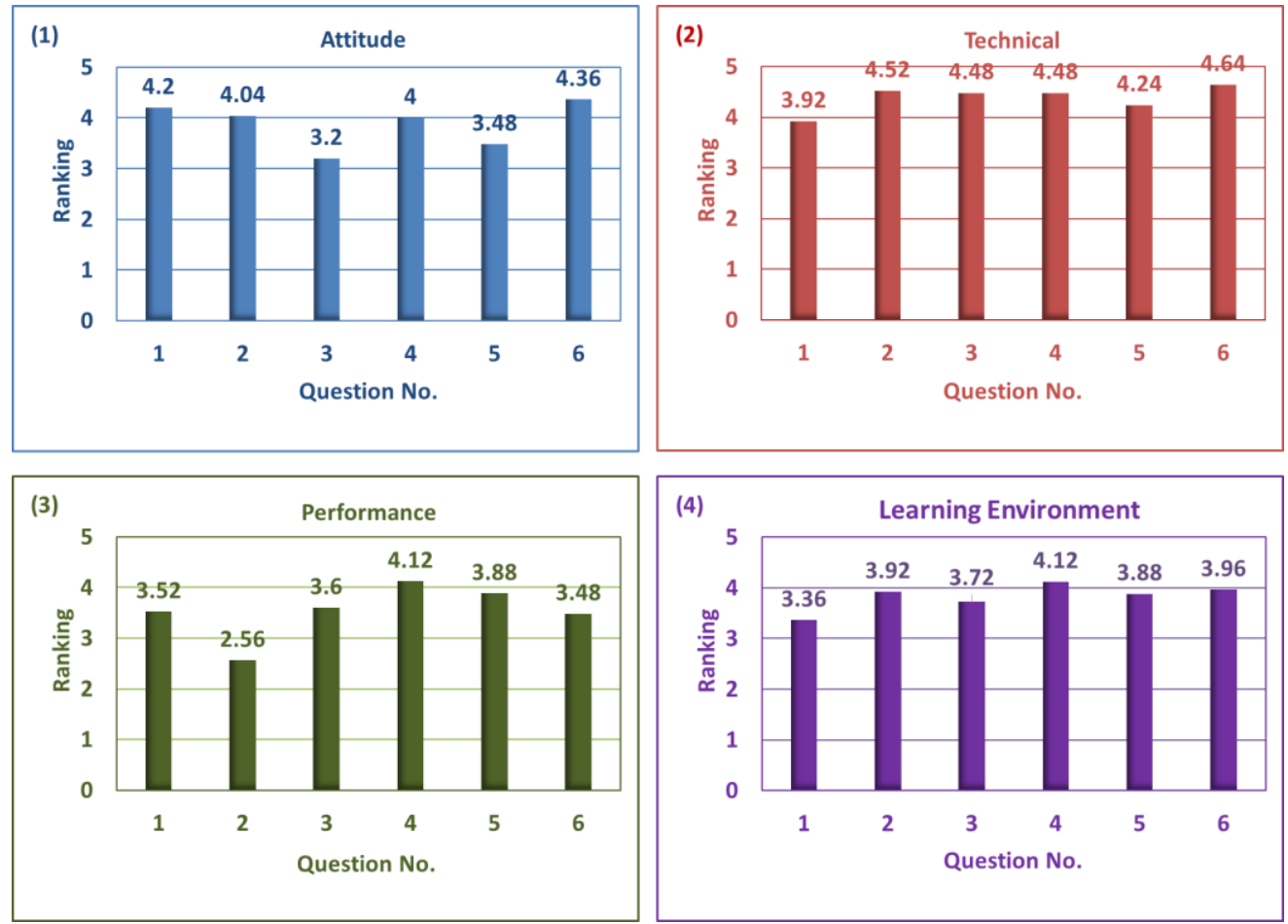

Figure 6. Bar charts showing students' perceptions: (1) Attitude, (2) Technical, (3) Performance and (4) Learning Environment. 


\subsection{Discussion of students' perceptions linking pedagogic theories and benefits}

From the results above in Table 2 and Figure 6, it is evident that the views of the students towards using Mentimeter was affirmative.

The students found Mentimeter formative assessment enjoyable (Figure 6(a)). They also recognised that Mentimeter helped them to pay attention in the class. Mentimeter quiz was found to be interesting in another study (Hill and Fielder, 2017) as well. Little (2016) also suggest that the Mentimeter activities can increase the focus and enjoyment of the students. It has potential to increase the student attendance like other Clickers (Greer and Heaney, 2004). In the present study, students also preferred Mentimeter over other conventional technology such as the Clickers. To bring the Clickers and distribute them to all of the student in a large class has been taken as a burden for some lecturers (Hwang et al., 2015). At the same time, raising hand is not out of concern as the data regarding the students' answer get lost once their hands are down (Abrahamson, 2006). Some of the comments of the students are presented in Table 3.

Table 3. General comments of students' perceptions about Mentimeter.

\section{Complimentary Comments}

"I really enjoyed using the Mentimeter because it is much more reliable than the electronic voting system (EVS) Clickers. Also, since it is available on your phone, almost everyone can access it easily as $99 \%$ of people own a smartphone. Inclusive. Consolidate learning. Makes lectures more interesting."

"I think it would be perfect. You can know if the app is working or not but in Clickers you don't."

"Mentimeter shows faster response by the system and easier to compare other people's opinion or choices. It's a much better technique than Clickers."

"It's good, it gets students to engage, recap, apply and conclude material in the lecture and it gets people to speak to their colleagues."

"Mentimeter is very useful when it comes to the end of lecturer quiz. I can use the information that I learnt in the lecture to answer the Mentimeter quiz. Overall, I think it is very useful in large class lectures." 
"I found it really innovative, easy to use and very interactive. I have not used anything like this in my previous school/college and enjoy using Mentimeter. It was a good thing to look forward to after covering the topic."

"Interaction, a new concept, has potential."

"Easy to use, opens quickly, enables students to interact and learn in an engaging way."

"Mentimeter is a good way to engage all the students in large classes. EVS is a bit technical as we have to change the channel in different rooms and we cannot know if we are connected or not but in Mentimeter we know we are not connected."

"A normal lecture room usually has more than 200 students which makes it hard for the teacher to engage with the students. Mentimeter makes it easy. It also helps students to participate in the lecture more confidently."

"It allows everyone to participate and most importantly the student is sure about what he/she has selected."

"Mentimeter is very easy to use and it is one of the convenient ways of learning and understanding the topic. Definitely recommended."

"I think the use of Mentimeter in large class is to be recommended because it allows every student to participate and have a chance to apply their knowledge without waste of a lot of time since people all answer at once unlike raising hands waiting for people to speak their opinion one after the other, which takes time."

"It is a good method of interacting with the class with a large amount of students. It helped me to remember key points/notes better. I think it engages people with the lecture content in a better entertaining way."

"I would definitely recommend using Mentimeter in a large class. It makes it really easier for the students to interact and able to understand the course content better. I really like the way this tool is presented to students to enhance their studies and to also clear any doubts if they someone may have. Also, getting the prompt feedback makes it a great tool compared to other normal learning tools."

"I believe that Mentimeter offered an interactive fun and educational aspect to lectures that assisted in my learning in key subject areas. It added an element of fun to the lecture, learning other lectures. Promoted learning."

"As everybody has a smartphone with them and everybody loves using their smartphone, so, I strongly suggest using Mentimeter to further improve your 
knowledge in the module, especially in large classrooms. It's a fun way to make students learn and I, myself, have gained a lot of knowledge for the module and got good marks."

"Mentimeter was very helpful for me in understanding this module. I think Mentimeter is a good way to engage with students in large classrooms."

\section{Critical Comments}

"I found Mentimeter took up a vastly disproportionate amount of the lecture time and felt it was a poor substitute for actual teaching."

"Not recommended too disruptive and an excuse to mess around for some class members.

Using mobile and connecting it to the internet during the class could sometimes serve as a distraction."

\section{Technical Improvements}

"A reliable WiFi connection is essential. More reliable WiFi connection is essential. More statistics/feedback could be provided to students about their answers."

"There can be a slot for student ID or name in the begging so this can be used for phase testes as well."

"Have an extra phone ready in class in case some students forget their phone or run out of battery."

"Use a more stable and stronger WiFi connection in the room as sometimes the connection is weak and doesn't record the response causing delays and distribution."

\section{General Improvements}

"Not everyone will participate, I am not sure how to fix this perhaps an incentive could be offered, e.g. price for the highest scoring students across the semester."

"Use timer for every question."

"I think it can be improved if Mentimeter had device like EVS to access and answer the quiz. Some student may not have access through phones. Therefore, I think there should be a specific device for Mentimeter."

"Maybe adding some hint feature with the choices of question, to think more deeply about the right choice. This can make learning efficient by gaining more knowledge on that topic. It is still anyways a great tool to use." 
"There should be less anonymity, students should use their name, instead of derogatory terms for example. There should be a leaderboard, get points depending on how quick you answer, it boosts morale and act as an incentive."

According to the students, Mentimeter was technologically sound (Figure 6(b)). It was also user-friendly as evidenced by the number of positive comments presented in Table 3, which agreed well with Nosek (2017). Mentimeter is considered as an interactive tool (Rudolf 2017) and students in this present study also identified it as interactive and fast. However, the main drawback of using any web-based Clickers like Mentimeter is that it cannot be used without the internet. In the study of Hwang (2015), some students commented that the WiFi signal was not strong enough for all of the students in the classroom to use at the same time. Technical comments in Table 3 also highlighted the necessity of better $\mathrm{WiFi}$ connections to improve the user experience. Therefore, the universities should invest more on better WiFi connections in order to improve their learning experience.

Mentimeter helped students to perform well in their final test (Figure 6(c)). They understood the course content and applied their knowledge. The Bloom's taxonomy (Krathwohl, 2002) indicates that 'understand' and 'apply' are the cognitive processes by which thinkers encounter and work with knowledge (Figure 7). Mentimeter also helped in prompt feedbacks which is considered as a good practice (Chickering and Gamson, 1987). In this study, however, students did not find Mentimeter formative assessment quite challenging (Figure 6(c)). Therefore, 'Quiz' and 'Who will win?" (Table 1) type questions can be added along with the MCQ to make it more challenging. Moreover, Imperial College London is currently getting benefits from Mentimeter (Aronsson, 2017) by using it for formative assessment including pop quiz and exit pass. 


\section{Bloom's Taxonomy}

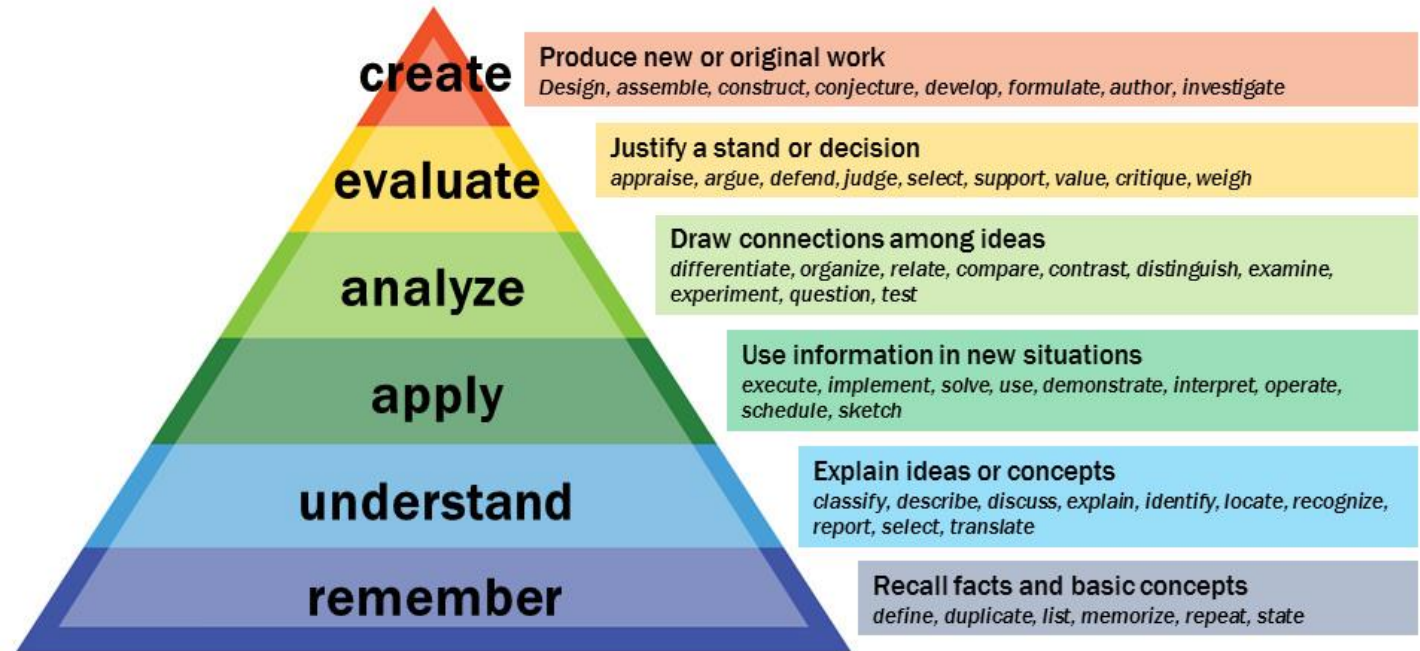

Figure 7. Creative Commons attribution on an image of the Bloom's Taxonomy

(Vanderbilt University, 2018).

Mentimeter has been proved to promote student engagement (Little 2017), participation, classroom interaction and inclusion (Hill and Fielder, 2017) which are the key factors for an effective learning environment. In this present study, students' perceptions have also supported these findings (Figure 6(d)) and complementary comments in Table 3. Using mobile phone-based ARS made classes more interactive and less boring (Treamblay, 2010). This classroom interaction can be of three types: learner-content, learner-instructor and learner-learner (Moore, 1993). Moreover, students also felt that Mentimeter encouraged active learning which is considered as one of the seven principles of good practice in undergraduate education (Chickering and Gamson, 1987). Nicol and Macfarlane-Dick (2006) argued that one of the seven principles of good feedback practice is "encourage teacher and peer dialogue around learning" and the histogram feedback of ARS can be used as a trigger for peer discussion and teacher-managed discussion in large class. Again, deep learners tend to share a constructive attitude toward using clickers, especially when perceived advantages of using the clickers in their learning and their peers are also using the clickers (Kelvin, 2017). A very few students disliked the use of Mentimeter in a large class. They found it to be a poor substitution for traditional lecture material as explained in the critical comments of Table 3. However, this could be improved by experience through a timely structured lecture session which offers a balance between lecture material and Mentimeter use. Overall, the response has been hugely positive and 
students' perceptions also suggest that it encouraged class discussion. Therefore, this present study established that the students are welcoming the use of Mentimeter in the large class as it promotes elements, such as interaction, inclusivity, engagement, and participation which are necessary for the high standard learning experience.

\section{Conclusion}

Overall, Mentimeter is easy to access, a powerful and flexible tool which has the solution to improve learning and teaching in the large class. It can play a key role in changing the dynamics of the large classroom by promoting active learning, student participation, and enjoyment. Formative assessment can be more interactive and fun using Mentimeter. The formative assessment data can also be stored and analysed further to design and manage the course. Students also appreciate that the technology integrated learning through Mentimeter has the pedagogical benefits. Teachers, on the other hand, can benefit from using Mentimeter to assess students' understanding and improve their own teaching style.

\section{References}

Abrahamson, L. (2006) A brief history of networked classrooms: Effects, cases, pedagogy, and implications. Audience response systems in higher education: Applications and cases, IGI Global, pp. 1-25.

Allen, D. and Tanner, K. (2005) infusing active learning into the large-enrollment biology class: seven strategies, from the simple to complex. Cell Biology Education, 4(4), pp. 262-268.

Beatty, I.D. (2005) Transforming student learning with classroom communication systems. arXiv preprint physics/0508129.

Bennett, R.E. (2011) Formative assessment: A critical review. Assessment in Education: Principles, Policy \& Practice, 18(1), pp. 5-25. 
Bergtrom, G., (2006) Clicker sets as learning objects. Interdisciplinary Journal of ELearning and Learning Objects, 2(1), pp. 105-110.

Burns, R.A. (1985) Information Impact and Factors Affecting Recall. Annual National Conference on Teaching Excellence and Conference of Administrators, Austin, TX (ERIC Document No. ED 258 639).

Caldwell, J.E. (2007) Clickers in the large classroom: Current research and bestpractice tips. CBE-Life sciences education, 6(1), pp. 9-20.

Cheung, G., Wan, K. and Chan, K., (2018) Efficient Use of Clickers: A Mixed-Method Inquiry with University Teachers. Education Sciences, 8(1), pp.31.

Chickering, A.W. and Gamson, Z.F. (1987). Seven principles for good practice in undergraduate education. AAHE bulletin, pp. 3-7.

Cline, K.S. (2006) Sharing teaching ideas: Classroom voting in Mathematics. Mathematics Teacher, 100(2), pp. 100-104.

Draper, S.W. and Brown, M.I. (2004) Increasing interactivity in lectures using an electronic voting system. Journal of computer assisted learning, 20(2), pp. 81-94.

Duzhin, F. and Gustafsson, A. (2018) Machine Learning-Based App for SelfEvaluation of Teacher-Specific Instructional Style and Tools. Education Sciences, 8(1), pp.7.

Elliott, C. (2003) Using a personal response system in economics teaching. International Review of Economics Education, 1(1), pp. 80-86.

El-Rady, J. (2006) To click or not to click: That's the question. Innovate: Journal of online education, 2(4), pp. 6.

Fleming, N.D. (2001) Teaching and learning styles: VARK strategies. IGI Global. 
Gibbs, G. and Simpson, C. (2004) Does your assessment support your students' learning. Journal of Teaching and Learning in Higher Education, 1(1), pp.1-30.

Greer, L. and Heaney, P.J. (2004) Real-time analysis of student comprehension: An assessment of electronic student response technology in an introductory earth science course. Journal of Geoscience Education, 52(4), pp. 345-351.

Hill, D.L. and Fielden, K. (2017) Use of Mentimeter to promote student engagement and inclusion. Pedagogy in Practice seminar, Carlisle, UK. Available at: < http://insight.cumbria.ac.uk/id/eprint/3473/> [Accessed: 5 March 2018].

Hwang, I., Wong, K., Lam, S.L. and Lam, P. (2015) Student Response (Clicker) Systems: Preferences of Biomedical Physiology Students in Asian Classes. Electronic Journal of e-Learning, 13(5), pp. 319-330.

Kay, R.H. and LeSage, A. (2009) Examining the benefits and challenges of using audience response systems: A review of the literature. Computers \& Education, 53(3), pp. 819-827.

Koppen, E. and Langie, G., (2013). Replacement of a clicker system by a mobile device audience response system. In Proceeding of the 41th SEFI annual conference 2013: Engineering Education Fast Forward, KU Leuven, pp. 1-8.

Krathwohl, D.R. (2002) A revision of Bloom's taxonomy: An overview. Theory into practice, 41(4), pp. 212-218.

Lam, S.L., Wong, K., Mohan, J., Xu, D. and Lam, P. (2011) Classroom communication on mobile phones-first experiences with web-based 'clicker'system. In ASCILITE-Australian Society for Computers in Learning in Tertiary Education Annual Conference, Australasian, pp. 763-777.

Little, C. (2016) Technological Review: Mentimeter Smartphone Student Response System. Available at: < http://blogs.cardiff.ac.uk/learning-technology/wp- 
content/uploads/sites/286/2017/04/mentimeter_article.pdf > [Accessed: 5 March 2018].

Lock. S. (2015) How Imperial College gets value from using Mentimeter. Available at: < http://www.emergingedtech.com/2015/03/how-college-gets-value-frommentimeter/> [Accessed: 5 March 2018].

Mentimeter, (2017a) Create fun and interactive presentations. Available at: <https://www.mentimeter.com/why> [accessed: 06 March 2018].

Mentimeter, (2017b) Mentimeter Features. Available at: < https://www.mentimeter.com/features> [accessed: 06 March 2018].

Micheletto, M.J. (2011) Using audience response systems to encourage student engagement and reflection on ethical orientation and behavior. Contemporary Issues in Education Research, 4(10), pp.9.

Moore, M. G. (1993) Editorial: Three types of interaction. The American Journal of Distance Education, 3(2), pp. 1-7.

Naismith, L., Sharples, M., Vavoula, G. and Lonsdale, P. (2004) Literature review in mobile technologies and learning. A NESTA Futurelab Series - report 11.

Nicol, D.J. and Macfarlane-Dick, D. (2006) Formative assessment and self-regulated learning: A model and seven principles of goodfeedback practice. Studies in higher education, 31(2), pp. 199-218.

Nicol, D. and Milligan, C. (2006) Rethinking technology-supported assessment practices in relation to the seven principles of good feedback practice. Innovative assessment in higher education, pp. 64-77.

Nosek, M. (2017) Mentimeter and PollEverywhere - Audience Response Systems Introduction. Avaiilable at: <http://blogs.cardiff.ac.uk/learning- 
technology/2017/04/28/mentimeter-and-polleverywhere-audience-response-systemsintroduction/> [Accessed: 5 March 2018].

Pelton, L.F. and Pelton, T. (2006) Selected and constructed response systems in mathematics classrooms. Audience response systems in higher education: Applications and cases, IGI Global, pp. 175-186.

Pettit, R.K., McCoy, L., Kinney, M. and Schwartz, F.N. (2015) Student perceptions of gamified audience response system interactions in large group lectures and via lecture capture technology. BMC medical education, 15(1), pp. 92.

Rudolph, J. (2017) A brief review of Mentimeter-a student response system. Journal of Applied Learning and Teaching, 1(1), pp. 22-30.

Simpson, V. and Oliver, M. (2007) Electronic voting systems for lectures then and now: A comparison of research and practice. Australasian Journal of Educational Technology, 23(2), pp. 187-208.

Skinner, B. F. (1968) The Technology of Teaching. New York: Appleton-CenturyCrofts, 19(3) pp. 271.

Tremblay, E. (2010) Educating the Mobile Generation-using personal cell phones as audience response systems in post-secondary science teaching. Journal of Computers in Mathematics and Science Teaching, 29(2), pp. 217-227.

Vanderbilt University (2018) Bloom's Taxonomy. Vanderbilt University Centre for Teaching. <https://cft.vanderbilt.edu/guides-sub-pages/blooms-taxonomy/ > [Accessed: 23 March 2018].

Wan, K., Cheung, G. and Chan, K. (2017) Prediction of Students' Use and Acceptance of Clickers by Learning Approaches: A Cross-Sectional Observational Study. Education Sciences, 7(4), pp.91. 